This PDF is a selection from an out-of-print volume from the National Bureau of Economic Research

Volume Title: The Mining Industries, 1899-1939: A Study of Output, Employment, and Productivity

Volume Author/Editor: Harold Barger and Sam H. Schurr

Volume Publisher: NBER

Volume ISBN: 0-87014-042-6

Volume URL: http://www.nber.org/books/barg44-1

Publication Date: 1944

Chapter Title: Petroleum and Natural Gas

Chapter Author: Harold Barger, Sam H. Schurr

Chapter URL: http://www.nber.org/chapters/c6326

Chapter pages in book: (p. 188 - 208) 


\section{Petroleum and Natural Gas}

IN TERMS of value, the production of petroleum, natural gas and byproduct natural gasoline is the most important mining activity in the United States. Our over-all indexes of production, employment and productivity are strongly influenced by the movement of this component of the total, and certain outstanding characteristics of the indexes of output and productivity are directly traceable to the role played by petroleum and natural gas in mineral enterprise as a whole. Unfortunately this industry, which is so important, is not representative of mining in general. Indeed it is in many respects unique, a fact which underlies many of the problems associated with the derivation and interpretation of the statistical measures for the industry.

To begin with, the production process differs markedly from that prevailing in most other mining industries. ${ }^{1}$ Except in rare instances petroleum and natural gas have not really been "mined" in this country. Shafts are not sunk into the underground formations so that the petroliferous sands may be dug out. ${ }^{2}$ Instead the underground oil-bearing formations are penetrated by means of wells, and often the actual production process consists of little more than harvesting the free flowing oil and gas and controlling the rate of flow. If the oil does not flow freely-as is usually the case after the early period of production-it may become necessary to lift the oil by artificial means.

These steps make up the actual "extraction" process. However, "mining" of most minerals is commonly defined to include not only the operations of extraction proper, but also certain associated tasks of cleaning the mineral (beneficiating), as well as operations designed to prepare the mineral body for future ex-

1 At least two industries have utilized production techniques which bear some resemblance to those in petroleum and natural gas: they are salt and sulfur. We do not include salt in our indexes, and sulfur is nowhere treated separately in the discussion.

2 Such methods of petroleum extraction have been used in some foreign countries. In the United States "mining" of petroleum has been tried, but with no commercial success. See G. S. Rice, "Mining Petroleum by Underground Methods," U. S. Bureau of Mines, Bulletin 351 (Washington, 1932). 
ploitation. In the petroleum and natural gas industry the last activity-usually called development work-is of very great importance. Oil and gas wells are typically short lived and production has, in the past, been maintained or increased only through the continual drilling of new wells. This work of new construction normally occupies a very much larger part of the industry's labor force than does similar work in other industries. In 1939, for example, about one fourth of the manhours of employment at petroleum and natural gas operations were apparently absorbed in the construction of new wells. ${ }^{3}$

In addition to development work and the purely extractive operations of the industry there is also the production of natural gasoline, which is quite distinct from the production of either petroleum or natural gas. The latter two are direct products of the well, and are, in fact, very often produced from the same wells. ${ }^{4}$ Natural gasoline, on the other hand, represents a secondary stage of production, for it is derived from natural gas, one of the primary products. To be sure, the production process utilized is by no means as elaborate as actual petroleum refinery operations, but nonetheless it is clearly a stage or so removed from the simple process of taking mineral from the earth. It may be considered as comparable with certain of the more elaborate beneficiating techniques used in the treatment of copper, lead and zinc ores, ${ }^{5}$ for example, although it is functionally different from them.

The industry is further set apart from other mining industries by the fact that much of the work of production and development is handled by contractors. Drilling of wells and associated tasks of derrick and rig building have long been performed in many fields by contract specialists. In recent years, moreover, other and more routine tasks of oil and gas field maintenance have been contracted out. All told, contract work accounted for about 25 percent of all manhours of employment in this industry in $1939 . .^{\circ}$ The

3 Census of Mineral Industries, 1939, "Crude Petroleum and Natural Gas," released May 1942, and "Oil and Gas Field Services Performed by Contractors," released December 1941.

4 Of the total output of natural gas in 1939, 45 percent came from oil wells and the remainder from wells which produced only natural gas (Minerals Yearbook, Review of 1940, p. 1032; ratio derived from gross production figures).

5 See Chapter 7 above.

6 Figures derived from preliminary releases of the Census of Mineral Industries, 1939, on "Petroleum and Natural Gas." "Natural Gasoline" and "Oil and Gas Field Services Performed by Contractors." 
extent of contract employment here may be compared with that in other major mining industries, where such employment is of minor consequence. ${ }^{7}$ Pennsylvania anthracite is an outstanding exception, but even in this field, where much of the strip mining is done by contractors, contract manhours accounted for less than 4 percent of total manhours in $1939 .^{8}$

It is not because there is any real difference between the product of contractors on the one hand, and regular operators on the other, that we point to contract employment as a distinctive feature of the petroleum and natural gas industry. The significance of contract work lies in the fact that because of the peregrinating nature of contract activities (and perhaps also because of the impermanent character of some contract enterprises), they are usually not adequately covered in official canvasses. In the petroleum and natural gas industry we find that with the exception of the 1902 and 1939 Censuses, no appreciable attempt to cover contractors has ever been made. For this reason it is necessary to rely on estimates of contract employment, and these are, in the nature of things, unsatisfactory. ${ }^{9}$ To exclude contract employment entirely would be even less satisfactory than to attempt to estimate its magnitude, for the data on physical output do not permit any distinction between contract and noncontract goods. Since contract employment has been of shifting importance, its exclusion would necessarily upset historical comparisons of productivity.

\section{THE RELATION BETWEEN OUTPUT AND EMPLOYMENT}

Before we consider the behavior of the index of productivity it is advisable to comment briefly on the nature of the index of physical output of the petroleum and natural gas industry. This index is derived from series relating to the output of the industry's three products: petroleum, natural gas and natural gasoline. ${ }^{10}$ The basic output and price data are given in Appendix Table A-l. It will

7 In bituminous coal, copper and iron, for example, contract manhours were less than 1 percent of regular manhours in 1939. For data on contract employment see 1939 Census of Mineral Industries, "General Contract Services for Mineral Industries" released December 1941.

${ }^{8}$ See the 1939 Census release cited in the preceding footnote, and also the release on Pennsylvania anthracite.

9 See notes to Appendix Table A-3.

$10 \mathrm{O}$ il and gas wasted is not included. 
be noted that for years before 1919 we have separated Pennsylvania grade from all other petroleum. Actually one may distinguish three main types of petroleum-paraffin-base, asphalt-base, and mixed-base-which exhibit significant price differentials. Paraffin-base, or Pennsylvania grade oil, commands the highest price because it is lightest in weight, most fluid, and particularly rich in gasoline, wax and lubricants. The production of this grade of oil has been slight in recent years, but in the earlier years covered by our analysis paraffin-base petroleum was of much greater importance than it is today. From 1899 until 1919 its representation in the industry's output shrank continually; since 1919 it has failed to recover its earlier importance. Because of the higher price which Pennsylvania grade commands, failure to take account of this shift in the composition of the industry's output would have resulted in an upward bias. Therefore we estimated Pennsylvania grade production for the period 1899-1919 by combining the output of New York, Pennsylvania, West Virginia, and southeastern and central Ohio. Since we were unable to divide the remainder into the two general grades of oil included, we used a single series for all other grades.

Our indexes of output and employment for the petroleum and natural gas industry, along with our index of productivity, are plotted in Chart 42. Although the lines extend over the period 1902-39 they are formed by connecting points representing very few years: 1902, 1929, and 1935-39. Our index of physical output for the industry covers all years during this period; but employment data, unfortunately, are available only for those years which have been plotted and in terms of manhours alone. ${ }^{11}$ All we can obtain, then, is a picture of the long run changes in the relationship between output and employment in the industry. This picture shows that both output and employment increased greatly over the period. Between 1902 and 1939 output multiplied eleven times, a larger gain than that achieved by any other mining industry. Over the same period manhours of employment more than doubled, but this is a much smaller rate of growth than that recorded for output.

Despite the apparent decline in employment between 1929 and 1939, the net increase in manhours of employment over the entire A-3.

11 The industry's employment data are discussed in notes to Appendix Table 
Chart 42

OIL AND GAS WELLS

Output, Employment and Productivity, $1902-39$

(1902: 100)

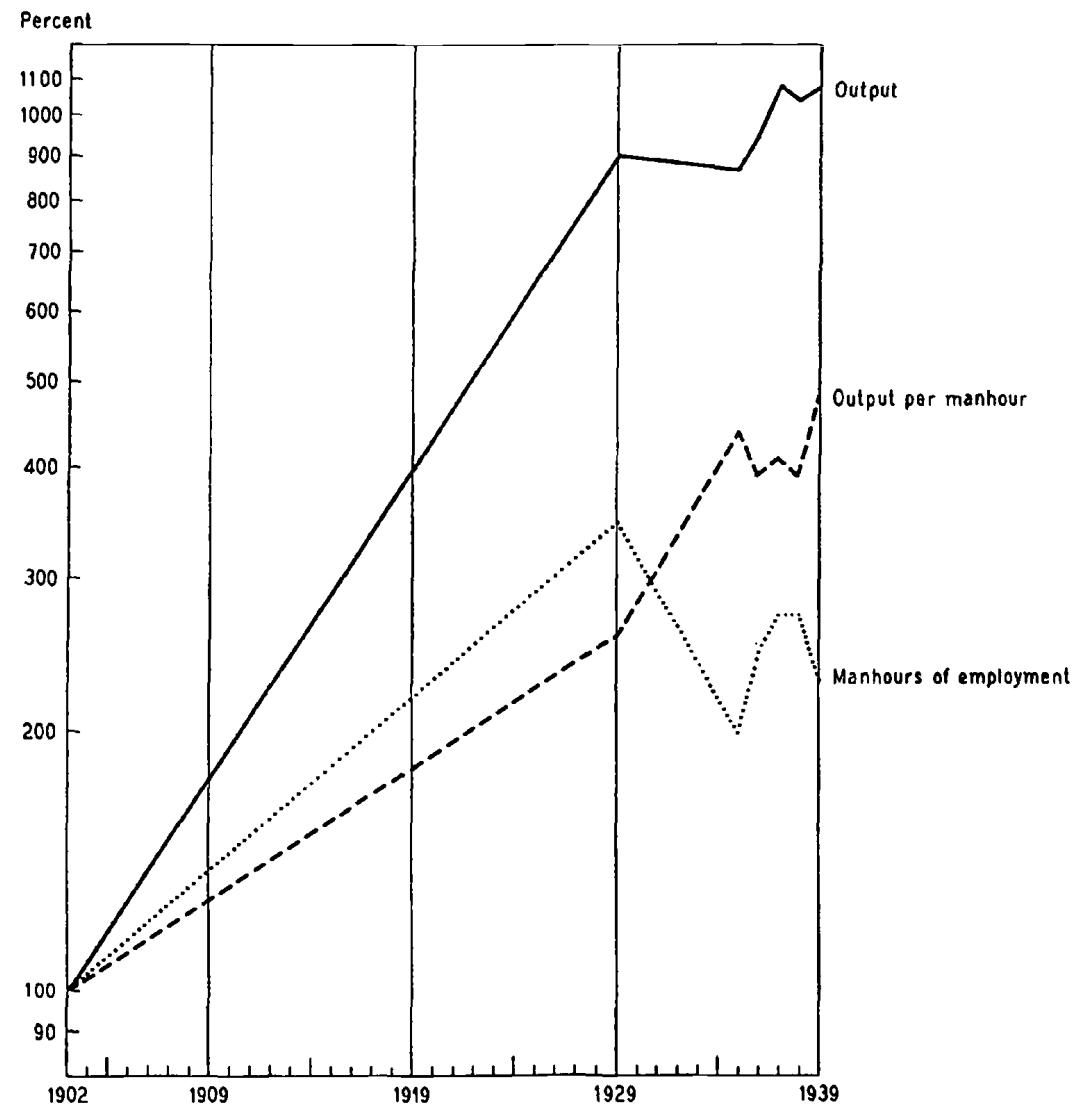

Ratio scale

For source and notes see Appendix E

period covered by our study puts the industry in a class by itself (see Table 11 above). In all other mining industries for which we have data on manhours over the same period (with the sole exception of gypsum) the net change was negative. This result is especially noteworthy in view of the fact that oil and gas wells also rank near the top when the various mining industries are arranged in order of increase in manhour productivity during the period. Over the four decades the rise in output was more than sufficient to offset the rise in the industry's productivity-so great, indeed, that employment rose more than in any other major branch of 
mining. The birth of the petroleum industry antedates the Civil War; but the expansion in its market and the advances in its technology alike suggest a new rather than an old industry.

As in the case of other mining industries, our measure of the productivity of oil and gas wells is a simple ratio of output to employment. In addition to the usual ambiguities surrounding such a measure of productivity, this industry is affected by some of its own. A few of the reasons for the ambiguities in the productivity measure for the industry have been touched on in the first section of this chapter. Let us explore them somewhat further at this point.

The concept of output per manday or manhour is a fairly simple one when the efforts of a man-or a man and a machine-materialize in a product. The product may be a good or a service, it may be tangible or intangible, but, in any case, it can be attributed directly to labor expenditure and machine utilization.

Picture now a free-flowing oil well with an attendant on hand to control the flow. The attendant opens a valve so much and a certain volume of oil is released during a given time period: he opens the valve somewhat more and a larger volume of oil is released during a time period of equal length. In the second case output per manhour is greater than in the first case, but is this due to more efficient expenditure of labor or to more intensive utilization of machinery-or is it just a windfall gain, a kind of unearned increment?

Once more, picture two oil wells just coming into production. Large volumes of natural gas are being released in the process. At one well, whatever the reason, the gas is allowed to blow into the air and is wasted; at the other, the flow of gas is controlled and the gas is marketed. In the first case the well produces only oil, in the second case it produces both oil and gas. To what may we attribute the larger production of the second well? The closest we can come to duplicating this situation is the production of some of the nonferrous metals, where byproduct metal can be recovered with improved beneficiating techniques. Sometimes the byproduct metals are recovered, sometimes they are not. But if they are recovered it is at the expense of some labor and machine effort. In the case of natural gas the increased production may be attributable also to increased expenditure of effort. More likely, however, it can be credited to the design of the well, or to in- 
creased knowledge of the geology of oil and gas fields and of the behavior of oil and gas when underground reservoirs are tapped.

These are not hypothetical situations. A deliberate restriction of the flow of oil marked many flush production fields in which control schemes were instituted between 1926 and the end of our period of study. The conservation and use of natural gas that was formerly wasted represents a long-time change in technology which has been typical of the industry. Each of these phenomena renders the interpretation of productivity measures more difficult than would otherwise be the case.

Again, the output of the industry, as measured by our index, consists of petroleum, natural gas and natural gasoline. Yet it is conceptually possible that in a single year there could be a high volume of industrial employment without the production of any of these three products. This could occur if all of the labor during the year were expended in exploration for wells and in drilling, and if there were no production by old wells while the new wells remained uncompleted at the year's end. Would the industry have produced nothing in that year? Obviously not. It clearly produced wells which would go into production, say, in the following year. But the construction of new wells is not included in our index of physical output; in such a case, then, we should obtain a productivity ratio of zero.

From this admittedly extreme and unlikely case it becomes apparent that our definition of output is perhaps too narrow, or our definition of employment too broad. Although both definitions may be defended on grounds of statistical expediency, it is nonetheless clear that an incomparability between output and employment exists. The importance of the incomparability when year-toyear comparisons are made is determined by two factors: (1) the absolute magnitude of well-development work, and (2) the relative importance of such development work from year to year. If the absolute magnitude is slight (as is true in most other mining industries ${ }^{12}$ ) or relatively constant, we may disregard the influence of development activities on the index. As we have seen, however, work of this sort is particularly important in the petroleum industry, and, as Table 18 suggests, it is more likely to shift from

12 The only other industry here discussed in which development work is sufficiently important to create a similar difficulty is open cut iron mining: see below, Chapter 11. 
TABLe 18

OIL AND GAS WELLS, 1899-1940

Thousands, except where percentages are shown

\begin{tabular}{|c|c|c|c|c|c|c|c|}
\hline \multirow[b]{2}{*}{ rear } & \multicolumn{5}{|c|}{ Wells Drilled during $Y_{e a r^{\mathrm{a}}}$} & \multicolumn{2}{|c|}{ Oil Wells } \\
\hline & Oil & Gas & Dry & Total & $\begin{array}{l}\text { Dry as } \\
\text { Percent } \\
\text { of Total }\end{array}$ & $\begin{array}{c}\text { Producing, } \\
\text { December } \\
31^{\mathrm{b}}\end{array}$ & $\begin{array}{l}\text { Drilled as } \\
\text { Percent of } \\
\text { Producing }\end{array}$ \\
\hline 1899 & 11.6 & c & 2.7 & 14.4 & 19 & .. & $\cdots$ \\
\hline 1900 & 13.7 & c & 3.4 & 17.1 & 20 & $\ldots$ & $\ldots$ \\
\hline 1901 & 11.8 & c & 3.3 & 15.1 & 22 & .. & .. \\
\hline 1902 & 13.0 & c & 3.4 & 16.5 & 21 & . & .. \\
\hline 1903 & 15.2 & .3 & 3.7 & 19.2 & 19 & . & .. \\
\hline 1904 & 16.0 & .4 & 4.1 & 20.5 & 20 & . & .. \\
\hline 1905 & 12.6 & .4 & 3.6 & 16.6 & 22 & $\ldots$ & $\ldots$ \\
\hline 1906 & 14.6 & .5 & 3.8 & 18.8 & 20 & . & .. \\
\hline 1907 & 15.5 & .6 & 3.6 & 19.7 & 18 & .. &.. \\
\hline 1908 & 13.2 & .6 & 3.1 & 17.0 & 18 & .. & $\cdots$ \\
\hline 1909 & 13.9 & 1.1 & 3.5 & 18.5 & 19 & - & $\cdots$ \\
\hline 1910 & 11.0 & 1.5 & 2.5 & 15.0 & 16 & .. & . \\
\hline 1911 & 9.8 & 1.6 & 2.4 & 13.8 & 17 & .. & . \\
\hline 1912 & 12.5 & 1.8 & 2.9 & 17.2 & 17 & . & $\cdots$ \\
\hline 1913 & 19.1 & 2.5 & 4.0 & 25.6 & 16 & .. & $\cdots$ \\
\hline 1914 & 16.7 & 2.4 & 4.2 & 23.2 & 18 & .. & . \\
\hline 1915 & 9.2 & 2.0 & 3.0 & 14.2 & 21 & . & $\cdots$ \\
\hline 1916 & 18.8 & 1.8 & 4.0 & 24.7 & 16 & .. & .. \\
\hline 1917 & 16.6 & 2.0 & 4.9 & 23.5 & 21 & .. & . \\
\hline 1918 & 17.9 & 2.3 & 5.6 & 25.8 & 22 & .. & .. \\
\hline 1919 & 21.0 & 2.2 & 6.1 & 29.3 & 21 & . & . \\
\hline 1920 & 24.3 & 2.3 & 7.5 & 34.0 & 22 & .. & $\cdots$ \\
\hline 1921 & 14.7 & 2.1 & 5.2 & 22.0 & 24 & 274 & 5.3 \\
\hline 1922 & 17.3 & 2.0 & 5.5 & 24.8 & 22 & 285 & 6.1 \\
\hline 1923 & 16.2 & 2.3 & 6.2 & 24.8 & 25 & 290 & 5.6 \\
\hline 1924 & 14.8 & 2.2 & 5.0 & 21.9 & 23 & 299 & 4.9 \\
\hline 1925 & 16.6 & 2.3 & 6.7 & 25.6 & 26 & 306 & 5.4 \\
\hline 1926 & 19.0 & 2.3 & 8.0 & 29.3 & 27 & 319 & 6.0 \\
\hline 1927 & 14.4 & 2.5 & 7.2 & 24.1 & 30 & 323 & 4.5 \\
\hline 1928 & 12.5 & 2.7 & 7.1 & 23.3 & 30 & 328 & 3.8 \\
\hline 1929 & 15.6 & 2.9 & 7.9 & 26.4 & 30 & 328 & 4.7 \\
\hline 1930 & 11.6 & 2.9 & 6.7 & 21.2 & 32 & 331 & 3.5 \\
\hline 1931 & 6.8 & 2.0 & 3.7 & 12.4 & 29 & 316 & 2.1 \\
\hline 1932 & 10.4 & 1.0 & 3.6 & 15.0 & 24 & 322 & 3.2 \\
\hline 1933 & 8.1 & .9 & 3.3 & 12.3 & 27 & 327 & 2.5 \\
\hline 1934 & 12.5 & 1.4 & 4.3 & 18.2 & 24 & 333 & 3.8 \\
\hline 1935 & 15.1 & 1.4 & 4.9 & 21.4 & 23 & 341 & 4.4 \\
\hline 1936 & 17.8 & 2.1 & 5.3 & 25.2 & 21 & 349 & 5.1 \\
\hline 1937 & 22.1 & 2.8 & 6.4 & 31.4 & 20 & 363 & 6.1 \\
\hline 1938 & 18.4 & 2.2 & 6.0 & 26.7 & 23 & 370 & 5.0 \\
\hline 1939 & 17.5 & 2.1 & 6.4 & 26.0 & 24 & 380 & 4.6 \\
\hline 1940 & 19.1 & 2.4 & 6.6 & 28.1 & 24 & 389 & 4.9 \\
\hline
\end{tabular}

For footnotes see next page. 
year to year than to remain constant. ${ }^{13}$ The absence of a clear and well defined correspondence in time between employment and the production associated with it makes the interpretation of our statistical measures more difficult. It must not be concluded, however, that the measures are therefore of little value. For it is possible to form an opinion of the relative importance of development work in different years, and thus to clarify our comparisons.

We may turn, after this brief introduction, to a consideration of the behavior of the industry's productivity index. Between 1902 and 1939 output per manhour at oil and gas wells increased nearly fivefold. ${ }^{14}$ No other major mining industry bettered this record: only the phosphate rock and gypsum industries show larger gains in productivity. In view of the small number of intervening years for which we have data, there is little we can say about other aspects of the case. We know nothing of what took place between 1902 and 1929 and are therefore not in a position to comment on changes in the rate of growth of productivity between these two years. Over the period as a whole there seems to be no evidence of a slackening in the growth of manhour output in the industry. Indeed, it appears from Chart 42 that the rate of increase after 1929 was more rapid than it had been dur-

13 We have endeavored to include both exploration and drilling activity in the industry's labor input, but the extent to which the employment figures do actually include development work is open to doubt. Employment in rig building and drilling, operations performed mainly by contractors, appears to be adequately covered. As for exploratory work, it is usually done by the larger producers on their own account, and they presumably report the employment to which it gives rise; but some of the smaller concerns may not adequately report their activities. The 1939 Census release on oil and gas field contract services is the only source to list exploration as a separate activity, and the amount of employment there reported is not large. For a description of the manner in which we derived our employment estimates, see the notes to Appendix Table A-3.

14 The available evidence suggests that there was no marked difference in the level of importance of development work in the industry between the years 1902 and 1939. In 1939 about one fourth of total manhours were devoted to well drilling; in 1902 the corresponding proportion was approximately the same, if we may judge from the ratio of contract to regular employment. For a discussion of the nature of contract activities, see U. S. Bureau of the Census, Special Reports, "Mines and Quarries, 1902," p. 724. According to our estimates contract manhours accounted for about 30 percent of total manhours in 1902, but this includes some work which was not strictly developmental in character.

Footnotes to Table 18.

- For 1899-1934, Oil and Gas Journal (Dec. 19, 1935), p. 12. These series are avail. able back to 1859 when drilling started. For 1935-40, Minerals Yearbook.

'Minerals Yearbook and its predecessor Mineral Resources. Data are not available for years prior to 1921.

- Fewer than 50. 
ing the period 1902-29.15 If the data we can assemble offer only tenuous evidence of changes in the rate at which productivity has grown, there is no question of the net rise over the long run. We shall attempt, therefore, to cast some light on the background of long period changes. As in other mineral industries we may consider the factors that have influenced productivity under two broad headings: resource conditions and technology.

\section{RESOURCE CONDITIONS}

When we speak of resource conditions as a factor influencing industrial productivity we mean the grade and accessibility of those resources which the industry is currently exploiting. That is to say, we are not concerned with the fact that depletion of oil and gas wells has normally proceeded at a very rapid rate. Such a condition will affect the behavior of an individual well's productivity over time, but will have little influence on an index of productivity for the industry if other wells or other pools come into production and replace the declining well or pool.

Viewed in this light, the grade of petroleum and natural gas resources has not declined during the period with which we deal. For the industry has been blessed with a seeming abundance of new fields to which production could constantly shift when older fields began to suffer from depletion. One of the outstanding characteristics of the history of oil and gas exploitation in this country has been the continual migration to new flush production areas. The National Research Project collected evidence on this point. Geographical centers of production were calculated and these indicate that since the early days of the industry in Pennsylvania, production first moved westward and then in a southwesterly direction. ${ }^{16}$ Such shifts in the areas of production were of course occasioned by the new discoveries which have played such an extraordinary part in the maintenance and expan-

15 This is the case despite the fact that schemes of production control introduced in the 1930's kept production of flush wells to a fraction of their potential. In addition, such schemes often operated to encourage excess well drilling which might be expected to affect the productivity ratio adversely on still another count. See U. S. Bureau of Mines release, "Recent Trends in Employment and Productivity in the Oil and Gas Fields" (April 24, 1939), p. 3. See also O. E. Kiessling and others, Petroleum and Natural-Gas Production (National Research Project, Philadelphia, 1939), pp. 44, 161-62; National Resources Committee, Energy Resources and National Policy (1939), pp. 198, 203.

16 Kiessling and others, op. cit., pp. 35 et seq. 
sion of petroleum output (Chart 43). The data indicate not only that these new fields have replaced fields of declining productivity, but that successive shifts in production have also been accom-

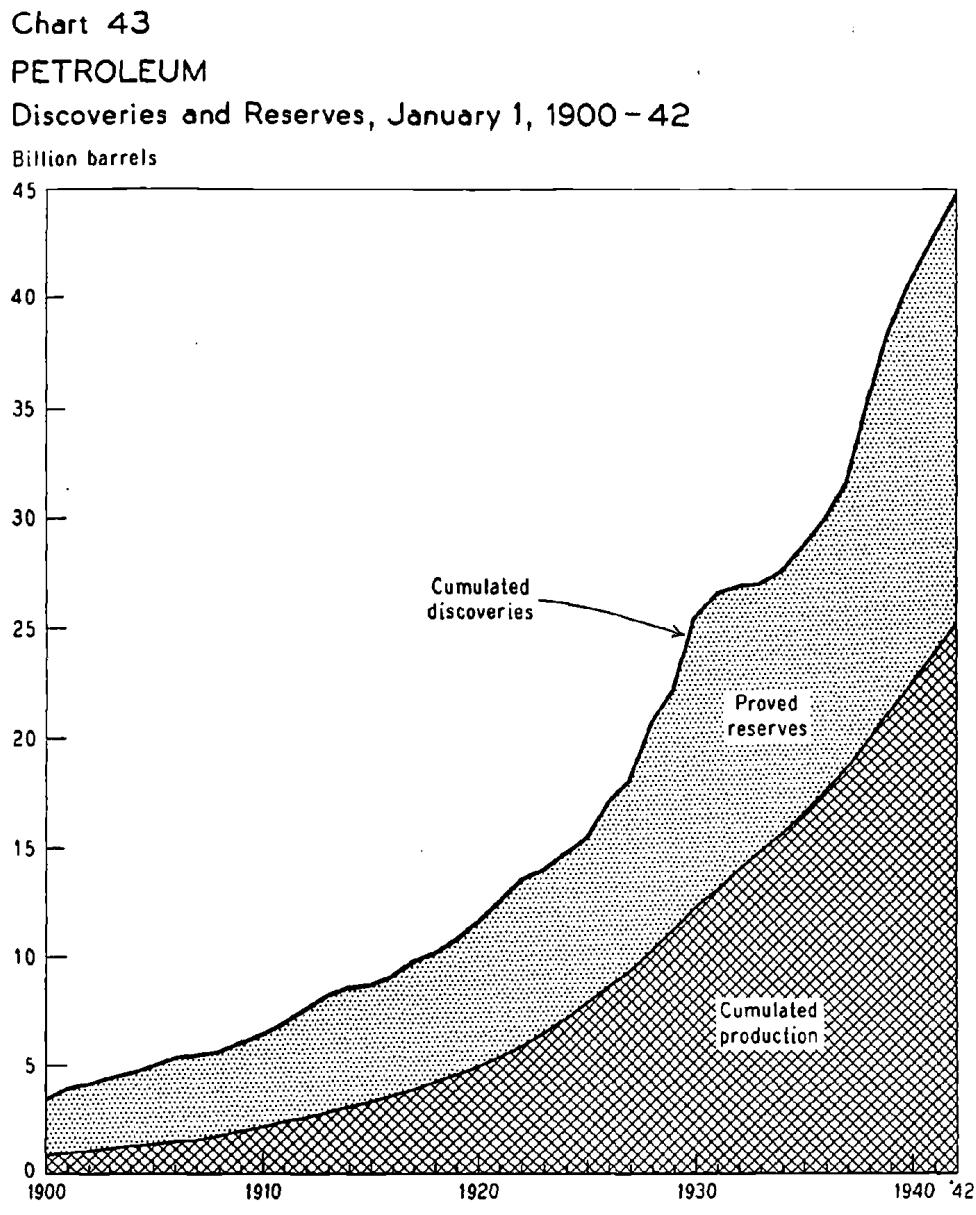

For source and notes see Appendix $E$

panied by higher levels of productivity per well than obtained in older fields even in their heyday. ${ }^{17}$

Although migration to new fields is thus seen to have favorably affected resource conditions in the industry, we must also note

17 Ibid., p. 44. This observation should be qualified, for it is evident that new fields have also utilized new production techniques. Hence any comparison made with peak production days of older fields suffers from the fact that those fields employed production techniques then current. Basically, however, this observation is well founded in view of the fact that the deeper formations struck in new fields have meant production with greater natural pressure. 
one negative factor in the situation. The oil and gas formations exploited in the newer fields of the West and South generally lie at a greater depth than the producing formations of an earlier day. Striking evidence on this point also is to be found in the National Research Project report on the industry. ${ }^{18}$ Greater depth usually has brought with it increased drilling difficulties, both because of the greater distances involved and because of the more troublesome formations encountered. In addition, until improved exploration techniques partially overcame this difficulty, increasing depth seems also to have resulted in a greater proportion of dry holes drilled. ${ }^{19}$ Dry holes, it should be explained, are drillings which produce no oil or gas, and so turn out a disappointment to those who drill them.

In general it may be said that technology has been able to cope with increasing difficulties of this nature. In any case, the obstacles shrink into insignificance beside the outstanding fact of resource plenty in the industry. ${ }^{20}$ It is clear, therefore, that a large measure of importance must be assigned to the pattern of resource occurrence in the industry when reasons for the rapid rise in productivity are sought.

\section{TECHNOLOGY ${ }^{21}$}

Bountiful resources have had a powerful ally in technology, which has operated on three fronts in the crude petroleum and natural gas industry: exploration, drilling and production. In other mining industries it is sufficient to consider only those advances that have been made in the operations included under the last of

18 Ibid., Figure 20, p. 192.

19 See Table 18. Note particularly the jump in the ratio of dry holes to total wells drilled in the 1920's. This is perhaps partially the result of the high level of production in these years, which stimulated exploration activity of all sorts.

20 It should be clear that we speak of resource plenty in a historical sense. We do not mean to imply that petroleum and natural gas resources are endless in this country, but rather that over the period considered by us the average grade of resources in current exploitation has not declined. The very prodigality with which new resources have been exploited-although it has resulted in a high level of manhour productivity-may have weakened the industry's future position with regard to resource abundance.

21 In writing the remainder of this chapter we have drawn heavily upon the following sources: O. E. Kiessling and others, Petroleum and Natural-Gas Production (National Research Project, Philadelphia, 1939); Max W. Ball, This Fascinating Oil Business (Bobbs-Merrill, 1940); and David D. Leven, Done in Oil (Ranger Press, 1941). 
these headings. However, as we have already had occasion to point out, development work is of unusual importance in this industry.

\section{Exploration}

Improvements in exploration techniques do not affect industrial productivity directly. We are interested in advances in this portion of oil industry technology, not because of their effect on labor requirements in exploratory operations, but because through them the location of new sources of oil and gas is made possible. As we have seen, the appearance of new fields has been a factor of strong significance in the history of the industry. In this respect the extraction of petroleum and natural gas differs from most other forms of mining in which the "finding of new ore bodies has been subordinated to economic extraction"; ${ }^{22}$ while other forms of mining have been characterized by the intensive exploitation of known resources, the petroleum and natural gas industry has been extending its resource frontiers.

This fact is plainly revealed in Table 19 in which the discoveries of new oil fields are compared with the discoveries of new metal mining districts. Whereas all of the 35 leading metal mining districts were discovered before the first decade of the present century, 36 out of the 50 leading oil fields discovered before 1933 were found after 1910. Moreover, when rates of discovery in the search for oil are calculated, it appears that the rate of discovery was increasing, at least until the period after 1930. It declined from 1931 to 1935 , having reached its long time peak between 1926 and $1930 .^{23}$

The constant replenishment of our oil and gas resources through new discoveries has been made possible, in good part, by the evolution of improved exploration techniques. In the early days of the industry and, indeed, well into the twentieth century,

22 See Chapter 5 above.

23 Wallace E. Pratt, "Discovery Rates in Oil Finding," Bulletin of the American Association of Petroleum Geologists, Vol. 21, No. 6 (June 1937), pp. 698-99. Pratt's method of calculating discovery rates over the period 1900-35 is as follows: The discovery of reserves is fixed as of the year during which the first commercial well was completed. These discoveries are summed for 5-year periods, and for the whole period. Then the percentage of the total discovered in each 5-year period is computed. This percentage represents the "rate" of oil discovery in that period.

Data cited in Energy Resources and National Policy suggest that the rate may once again have jumped in the period $1936-40$, although we cannot yet say whether it exceeded the 1926-30 peak. (See Table 6, page 134 of the report.) 
exploration was essentially unscientific. Prospectors tended to rely almost exclusively on various surface indications which were supposed to betray the presence of oil underground. The indicators were generally such things as oil seepages, deposits of asphalt and other bitumens, etc., and topographic features which empirical evidence had associated with oil. Such methods were far from foolproof, but the record suggests that they served nevertheless to uncover large reserves of oil and gas.

\section{TABLE 19}

\section{METAL MINING DISTRICTS AND OIL FIELDS}

Number Discovered, or First Developed, in the United States, 1840-1933 ${ }^{\text {a }}$

\begin{tabular}{|c|c|c|}
\hline Period & $\begin{array}{c}\text { Metal Mining } \\
\text { Leading } 35 \text { Districts }\end{array}$ & $\begin{array}{c}\text { Oil Fields } \\
\text { Leading } 50 \text { Fields }\end{array}$ \\
\hline $\begin{array}{c}\text { Before } 1840 \\
1840-49 \\
1850-59 \\
1860-69 \\
1870-79 \\
1880-89 \\
1890-99 \\
1900-09 \\
1910-19 \\
1920-29 \\
1930-33\end{array}$ & $\begin{array}{r}3 \\
2 \\
5 \\
4 \\
7 \\
7 \\
2 \\
5 \\
\ldots \\
\ldots \\
. .\end{array}$ & 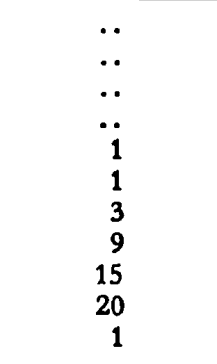 \\
\hline Totals & 35 & 50 \\
\hline
\end{tabular}

a Table and notes reproduced from Carter Goodrich and others, Migration and Economic Opportunity (University of Pennsylvania Press, 1936), p. 258.

${ }^{b}$ Districts producing gold, silver, copper, lead, zinc and iron that have yielded the largest value of product since earliest development. There are, of course, a great many lesser districts. Classification by decade usually relates to year of first significant production, and a number of these districts were first discovered much earlier. In several of these major districts there have of course been notable extensions, such as the Picher field in the Tri-State zinc and lead district. Alaska is not included.

- Compiled from tabulation in Oil and Gas Journal, issue of Oct. 31, 1935, with the addition of two Texas fields (Breckenridge and Electra) to the 48 there listed. The 50 fields have yielded 58 percent of the country's all-time production.

More recently such "practical" methods have been reinforced or replaced by a more scientific approach to the problem. The geologist with his expert knowledge of structural formations has been recruited by the industry in its effort to locate oil where surface indications are no longer of value. By the beginning of the postWorld War period most areas in which there were surface indications of oil had been thoroughly prospected, so that judgments based on geological theories of oil formations now became more acceptable. 
Since the early 1920's the geologist has been of invaluable assistance in exploration activities. In addition, the technological staff of the industry has come to include also the geophysicist, who devises methods of detecting oil through the utilization of precision instruments which can determine the physical properties of underground formations. One such method uses a magnetometer to determine the distance of iron-bearing, and particularly of metamorphic, rocks below the surface: where they come nearest to the surface the overlying sedimentary rocks are apt to be folded in an "anticline" which may contain oil. Another method employed by the geophysicist consists in placing electrodes in the surface of the earth at distances of a few hundred or a few thousand feet and passing a current through the intervening rocks: the drop in potential between different points gives a clue to the character of underlying strata. Still another method uses the sensitive torsion balance to measure minute variations in the force and direction of the earth's gravitational pull: by this means the density, and hence the character, of underlying formations may be ascertained. Finally, the geophysicist may explode a charge of dynamite, and use a seismograph to measure the timing and intensity of the tremors reflected by that which lies below. These various methods may be used individually or in combination: perfected by the geophysicist, their results are employed by the geologist.

Geology and geophysics have been aided by allied sciences in the discovery of new sources of oil and gas. Basically, however, they remain the two outstanding scientific techniques utilized, and together they have accounted for an ever-increasing portion of recent discoveries. They have not replaced random drilling entirely, but very few discoveries in recent years have been made by haphazard techniques. ${ }^{24}$

\section{Drilling}

The first oil deposits were discovered accidentally by persons drilling for salt brine, and the early methods of well drilling were taken over from the brine industry. The technique in almost universal use at that time (1860) employed the churn or cable drill, essentially a percussion instrument relying on gravity for its effec-

24 Kiessling and others, op. cit., pp. 60-63. 
tiveness. The original well which Drake drilled at Titusville, Pennsylvania, was less than 100 feet deep. He used a wooden derrick 30 feet high. The raising and lowering of the drill was achieved with a steam engine of the kind used in river steamboats. Most of the early drill tools were forged by local blacksmiths.

At the opening of our period, in 1899, the cable-tool system of drilling, operated by steam power, was still in the ascendant. Naturally it had been improved during the forty years of the industry's history prior to 1899 , but the principle had survived unchanged. The steam engine actuated a long seesaw, known as a walking-beam, in a vertical plane. The end remote from the engine was immediately over the well and the heavy drill tool was attached to it by cable. The drill tool was removed from the hole by a winding apparatus in the derrick. The cable drill is particularly effective in boring through hard rock, such as limestone, where great depths do not have to be attained. It has also the advantage that it can readily be used with a portable outfit, and thus moved from site to site. It is still employed extensively where these advantages are important.

The rotary drill, originally developed for boring artesian water wells, was first used by the oil industry in 1901. In this device the shaft is hollow and a stream of water is forced down inside the drill, returning in the space between shaft and rock. Thus the material removed by the drill is extruded automatically. It is no longer necessary, as with the cable drill, to interrupt operations periodically to remove cuttings from the drill hole. Further, the column of returning water or mud reduces the hazard of a cave-in of the well. On the other hand, unless a special form of rotary equipment which yields a solid core is employed (usually known as a diamond drill), rotary drilling yields less information about the strata penetrated than does the cable-tool: in a new field such information is important; in an old field it may not be of interest.

The rotary drill was originally used exclusively for drilling soft formations such as those found on the Gulf coast and in California, but with the development of roller and cone bits of alloy steel its application soon spread to other areas where harder materials had to be penetrated. The rotary drill proved particularly valuable in boring very deep wells, for it was necessary with the cable drill to reduce the diameter of the hole as drilling advanced. 
A rotary driven hole is the same diameter at the lower end as at the upper: on occasion rotary drills have pushed nearly three miles deep.

Another improvement in drilling technique relates to the operation of cementing the casing of the well. Special oil well cements, susceptible of continuous mixing, have been developed. Since several thousand sacks of cement may be needed to complete a single well, it is easy to perceive the importance of this innovation.

Since the opening of our period the technology of pressure control has advanced significantly, and it has become crucial in contemporary oil well operation. In earlier times, especially when the cable or churn drill was used, the completion of drilling was frequently heralded by the dramatic eruption of a fountain of oil. Besides wasting valuable oil, the early gushers often caught fire and caused much property damage. Nowadays even wells with very high pressures are brought into operation quite smoothly without the loss of any oil at all. This saving has been achieved by the use of the heavy column of mud-laden water, available with the rotary drill, to repress the oil and prevent its blowing out. In addition blow-out preventers, which can be closed around the drill pipe, are available in case of emergency. Testing and recording devices which reveal conditions at the foot of the well may also play a part in warning the operator of the approach of danger.

\section{Oil Well Operation}

Technological advances in oil well operation have been equally striking. The efficiency of recovery and the length of life of the well raise technological questions of the first importance. Thus in many of the early wells, which were allowed to gush or flow freely or were pumped by some simple device and subsequently abandoned, recovery reached only 10 to 20 percent of the total amount of oil in the sands or other strata. With modern techniques 70 or 80 percent of the oil may be obtained, leaving but a small fraction of the original deposit to be reached in some other way, perhaps eventually through mining.

Probably the earliest means adopted to increase the yield or prolong the life of the oil well was "shooting" or blasting with ex- 
plosive. In this method the charge is lowered to the foot of the well and there detonated, so that the surrounding strata may be shattered and the oil released. Where the oil is associated with limestone the injection of hydrochloric acid performs a similar function.

The principal agent which forces oil to the surface is, of course, the natural gas occluded in subsurface reservoirs. When a well no longer flows freely it may be abandoned, as indeed was often done before the knowledge that large amounts of oil remained in the ground stimulated the development of artificial measures for forcing it to the surface. One of the most interesting of these techniques is the restoration of the gas pressure by pumping air, or more usually gas itself, into the oil-bearing strata through an existing well or through a hole bored for the purpose. Apparently repressuring was first successfully undertaken in 1911; since then it has been widely used, especially in shallow fields where the natural pressure is insufficient to eject more than a small fraction of the total amount of available oil. ${ }^{25}$

If repressuring is uneconomical or difficult, perhaps because of the geological formation, other methods are available. Where the problem is not so serious as to require mechanical pumping, gas lifting methods may be used. Gas under pressure is forced through a pipe to the foot of the well, whence it returns with the oil to the surface. The gas is then collected, compressed, and used over again for the same purpose.

Where the well is too deep, or gas lifting methods alone are inadequate, resort must be had to pumping. Since oil can be sucked only from depths of 20 or 30 feet, the pumping mechanism must be placed within this distance of the bottom of the well and the oil forced from there to the surface. The operation is commonly accomplished by means of a rod inserted in the well and connected to the pump: the power used at the surface to actuate the rod is sometimes centralized for a number of wells by cables. Special difficulties are encountered in the case of very deep wells -say, more than 5,000 feet. Here special types of pump may be used-for example, hydraulically operated rodless pumps, or elec-

${ }^{25}$ Experiments in repressuring were originally undertaken as a means of utilizing surplus gas: they had already been begun some years before 1911 (A. Beeby Thompson, Petroleum Mining and Oil-Field Development, Van Nostrand, 1910, p. 92). 
tric pumps in which the motor is lowered into the well and fed by armored cable.

Because of the labor involved in drilling, the most important single influence upon the productivity of oil and gas wells in the long run is probably the proportion of available oil that is ultimately recoverable by the methods in vogue. The cost of drilling a well of a given depth is much the same whether only 40 percent, or as much as 80 or 90 percent, of the oil in the formation is actually recovered during the lifetime of the well. Hence it is to the interest of the individual operator to secure maximum recovery. ${ }^{26}$ The question is also an important one from the conservation standpoint, and it is likewise to the interest of the community that as little oil as possible be left in the ground. Once oil has ceased to flow, and can no longer be pumped, its recovery becomes hazardous and expensive, and there may in fact be no way in which such oil can ever be recovered.

The principal method by which the percentage of oil eventually recoverable may be increased is through the preservation of underground gas pressures, the artificial restriction of the flow of oil, and the consequent lengthening of the life of the well. This may be achieved by the use of valves at the surface; or by the insertion of tubing only 2 or 3 inches in diameter inside the casing of the well. It is obvious such methods reduce the rate of flow: it is not so obvious that they will improve eventual recovery. Regulation of flow contributes to the latter object in two principal ways. If a well is allowed to flow freely it may happen that the pressure at the foot of the well is insufficient to keep the natural gas in solution, in which case free gas will be obtained-gas that has made no contribution to the task of raising oil to the surface. With artificial reduction of the flow of oil the pressure at the foot of the well is maintained more nearly equal to the pressure in distant parts of the reservoir, and the expansion of a given amount of natural gas is made to raise a larger quantity of oil to the surface. The second way in which the regulation of the flow of oil contributes to its eventual recovery is by reducing the migration of subsurface water. It has been found that water moves more readily than oil in response to a given pressure gradient, and

26 However, if neighboring wells are rapidly draining the field, the attempt to maximize recovery for each individual well may merely encourage waste, and eventually leave much oil in the ground. It is nonetheless to the operators' common interest that the entire field shall be so exploited that maximum recovery results. 
moves through strata which are impermeable to oil. Where flow rates are excessive, underground pressure differences between various parts of the field are increased, and water is apt to work through coarse textured strata, thus cutting off oil in fine textured sands and rendering it irrecoverable by existing methods.

Where neighboring wells are operated by many different producers, these considerations do not diminish the immediate advantage which may accrue, or appear to accrue, to any individual producer through a policy of unrestricted production on his part. Such a policy may indeed diminish the eventual output of the field, but it may still yield the individual who pursues it a larger fraction of this smaller total. This is why more and more attention has been devoted to the desirability of framing state proration laws and other conservation measures, in order not only to prevent wells from being spaced too closely, but also to reduce the rate of flow of existing wells. ${ }^{27}$

We should note, finally, that measures such as those described, which diminish output now in order to increase eventual recovery, make the interpretation of productivity measures in the petroleum industry especially difficult. For a deliberate reduction in the rate of flow does not reduce the input of labor correspondingly, or indeed at all. Over the entire life history of the well, output per man may be the same as it would have been had no conservation measures been undertaken. Yet it is true, too, that in the early years of its life output per man is reduced by the practices adopted. The effect on our productivity index depends upon the age distribution of producing wells and their eventual life. Although the new conservation practices have probably depressed the level of productivity in recent years, in the long run they may lead to even greater output per man than would otherwise have been achieved. ${ }^{28}$ To have maximum significance, and to

27 "It is obvious that by lessening the waste of gas or reservoir energy proration increases the total amount of oil that will be recovered. The amount of this increased recovery will not be known for many years, until a large number of prorated fields have approached exhaustion and their recoveries can be compared with those of fields produced by former methods. All that can now be said is that the increase in recovery-the saving of oil that unrestricted production would have left in the ground-will be large" (Max W. Ball, This Fascinating Oil Business, p. 148).

28 Where conservation measures reduce current production per well, current productivity is depressed, but eventual recovery may be increased. If output and manhours are each summed over the entire life of the well, output per manhour may be increased, too. Productivity in recent years may also have been depressed by the tendency of proration, where carelessly administered, to encourage unnecessary drill. ing (see footnote 15 above). Here no long run benefit to productivity accrues. 
report the full benefits of technological change, productivity comparisons in the petroleum industry should probably be made over rather long periods, and between groups of years instead of between isolated years. It is all the more remarkable that the measures we are able to present, which are primarily a comparison between the two years 1902 and 1939, should reveal the substantial increase in output per manhour which they do in fact show. 